\title{
La ineficacia de la sanciones en los delitos contra el honor en los procesos judiciales del juzgado de investigación preparatoria de Tacna y su despenalización en el código penal peruano, en el año 2009-2010
}

The ineffectiveness of sanctions in against honor the offenses in judicial proceedings of the court of preparatory research and decriminalization of tacna in the peruvian penal code, in the year 2009-2010

\author{
Herminia Sarmiento Chambi ${ }^{1}$
}

\begin{abstract}
RESUMEN
Objetivo: Precisar la ineficacia de las sanciones tipificadas en los Delitos contra el Honor y si es necesaria su despenalización del Código Penal Peruano.

Método: El trabajo corresponde a una investigación aplicada, porque el investigador examina un problema lo explica; además, propone las soluciones jurídicas para que el fenómeno se transforme 0 perfeccione en aras de la justicia social. También es un tipo de investigación socio - jurídica porque se estudiaron los hechos y relaciones de orden social reguladas en normas jurídicas y porque se pretende determinar la ineficacia de las sanciones penales en los Delitos contra el Honor de las personas. Para tal propósito se consideró la información obtenida a través de la aplicación del Cuestionario, el Análisis Documental; y, la Cédula de Entrevista; como instrumentos de medición de las variables de estudio.

Resultados: De los expedientes analizados, al menos el $27 \%$ ha sido declarado en abandono; el $20 \%$ ha alcanzado sentencia absolutoria; otro $20 \%$ de los proceso ha sido archivado; el $11 \%$ ha sido declarado improcedente; el $10 \%$ han terminado en sobreseimiento; el $6 \%$ ha sido declarada inadmisible; el $5 \%$ de los expedientes ha alcanzado sentencia condenatoria; $y$, el $1 \%$ ha sido declarado nulo.

Conclusión: El $88 \%$ de los profesionales del derecho de la especialidad en materia penal manifiestan que las penas tipificadas en los delitos contra el honor son ineficaces, y por ello, es necesaria la despenalización de este tipo de delitos del Código Penal Peruano.
\end{abstract}

\section{PALABRAS CLAVE}

Delitos contra el Honor, Difamación, Calumnia, Injuria, Procesos Judiciales, Despenalización.

\begin{abstract}
Objective: Specify the ineffectiveness of the sanctions described in Crimes against the Honor and if decriminalization of the Peruvian Penal code is required.

Method: The work is for applied research, this level is given when the researcher examines a problem explains; also proposes legal solutions for the phenomenon to transform or improve for the sake of social justice. He's also a research partner - legal because they studied the facts and social relations regulated by legal norms and because it seeks to determine the ineffectiveness of the criminal penalties for offenses against the honor of the people. For this purpose we considered the information obtained through the application of the questionnaire, the documentary analysis, and the Certificate of Interview, as measuring instruments to study variables.

Results: Of the files analyzed at least $27 \%$ of the files have been declared abandoned, $20 \%$ have reached judgment of acquittal, another $20 \%$ of the processes have been filed, $11 \%$ have been declared inadmissible, $10 \%$ have ended in dismissal, $6 \%$ have been declared inadmissible, $5 \%$ of cases have reached conviction, and $1 \%$ have been declared invalid.

Conclusion: The $88 \%$ of legal professionals specialty in criminal sentences say they typified in honor crimes are ineffective and therefore it is necessary to decriminalize this type of crime Peruvian Penal Code.
\end{abstract}

\section{KEYWORDS}

Honor Crimes, Defamation, Libel, Slander, Judicial, Decriminalization

1. Magíster con Mención en Ciencias Penales, Abogada. Actualmente laboral como Directora del Centro de Conciliación NUEVO MUNDO y Conciliador Extrajudicial Especializado en Familia. Especialista en Transporte Terrestre de Pasajeros y Mercancías DRTyC.Tacna.

E-mail: hesarch@hotmail.com 


\section{Introducción}

La calumnia es un delito que consiste en la imputación a una persona de haber cometido un hecho constitutivo de delito siendo dicha afirmación falsa. Se diferencia de la injuria en que ésta es un simple insulto. Así, la expresión "ladrón" no supondría una injuria, sino una calumnia. Obra en su contra la llamada exceptio veritatis; esto es, que si el presunto calumniador puede demostrar que la expresión vertida es cierta, no hay culpa y, por tanto, no hay delito. Así, en la expresión anterior, sólo podrá ser condenado el que llama a otro "ladrón" sin poder demostrarlo.

En cuanto a la difamación; se define a la comunicación de una declaración que hace una afirmación falsa 0 verdadera, expresamente declarada o implícita de ser factual, dolosa, que puede dañar la reputación de un individuo, negocio, producto, grupo, gobierno o nación. La mayor parte de las jurisdicciones permiten demandas judiciales, civiles y/o criminales, para desalentar varias clases de difamación y responder contra la crítica.

La tipificación de los delitos contra el honor en el ordenamiento penal responde a que se asume como un bien que es de interés público proteger y reparar, no en términos de los daños y perjuicios a los que hubiese lugar y que son atendibles en el fuero civil, sino en términos del daño hecho a la sociedad en su conjunto.

La pregunta es si se debe sancionar estos delitos con prisión efectiva, que es lo que muchos ven como exagerado, y en segundo lugar si se debe despenalizar (sacar del Código Penal) la injuria, la calumnia, y la difamación. Es así que el parlamentario Javier Valle Riestra precisó que la injuria, la calumnia, y la difamación deben ser materia de juzgamiento en la vía civil, donde la persona deberá demandar a quien ha sido protagonista de estos hechos contra el honor, llevándose a cabo una audiencia ante el Juez para conciliar a las partes. Si no hay conciliación, el Juez escucha, ausculta las pruebas y dicta una sentencia condenando a una indemnización a favor del agraviado y a que se publique en un diario de mayor circulación la sentencia que descalifica a esa persona.

El presente trabajo de investigación busca precisar la necesidad de despenalizar los delitos contra el honor en el Código Penal Peruano (ineficaces); y es titulado: "La Ineficacia de las sanciones en los delitos contra el honor en los procesos judiciales del juzgado de Investigación Preparatoria de Tacna y su despenalización en el Código Penal Peruano, en el año 2009-2010".

\section{Materiales y métodos}

La población de estudio está comprendida en 100 Abogados especializados en materia penal y 120 Expedientes del Juzgado de Investigación Preparatoria, Magistrados en Materia Penal, (2190 abogados: Fuente Colegio de Abogados de Tacna). Asimismo, el objeto de estudio está referido a la despenalización de los Delitos contra el Honor; se analizaron para ello los expedientes judiciales al período 2009 - 2010. Para la recolección de datos se utilizaron el cuestionario, la ficha de observación y la entrevista.

\section{Resultados}

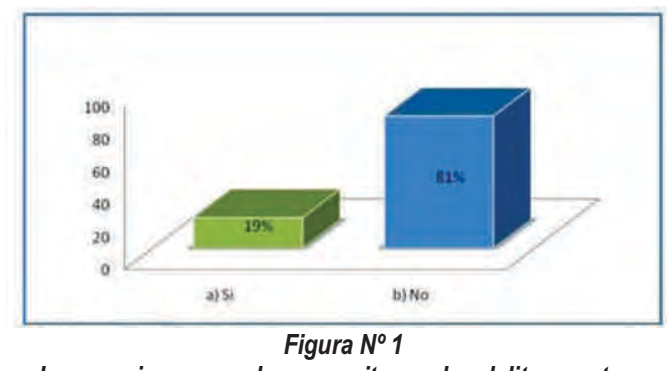

Las sanciones penales prescritas en los delitos contra el honor en el Código Penal Peruano - Prestación de Servicio Comunitario en su aplicación son viables.

El $81 \%$ de los encuestados señalan que Las sanciones penales prescritas en los Delitos contra el Honor el Código Penal Peruano Prestación de Servicio Comunitario en su aplicación "no" son viables; y sólo el 19\% manifiesta lo contrario (Figura № 1).

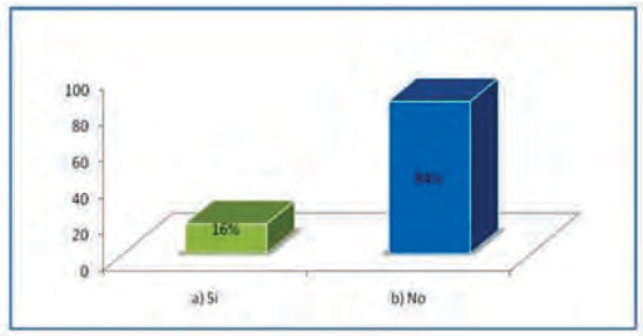

Figura $N^{\circ} 2$

Las sanciones penales prescritas en los delitos contra el honor cumplen un rol intimidatorio y regresivo para los sujetos que cometen dichos delitos.

El $84 \%$ de los encuestados manifiestan que las sanciones penales prescritas en los Delitos 
contra el Honor "no" cumplen un rol intimidatorio y represivo para los sujetos que cometen dichos delitos; y, sólo el $16 \%$ señala lo contrario (Figura $\mathrm{N}^{0}$ 2).

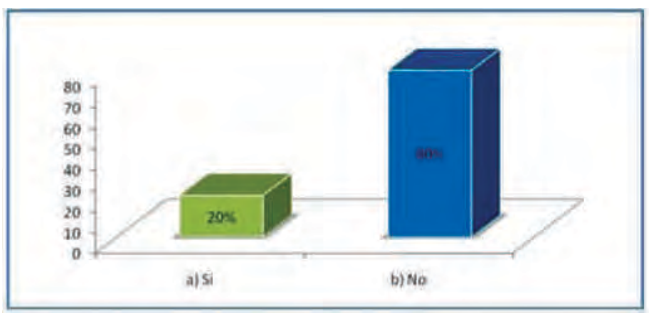

Figura $N^{\circ} 3$

Las sanciones penales prescritas en los delitos contra el honor protegen el bien jurídico del honor.

En la Figura $N^{0} 3$ se puede observar que el $80 \%$ de los encuestados consideran que las sanciones penales previstas en los delitos contra el honor; "no" protegen el bien jurídico del honor; y, el $20 \%$ señala lo contrario.

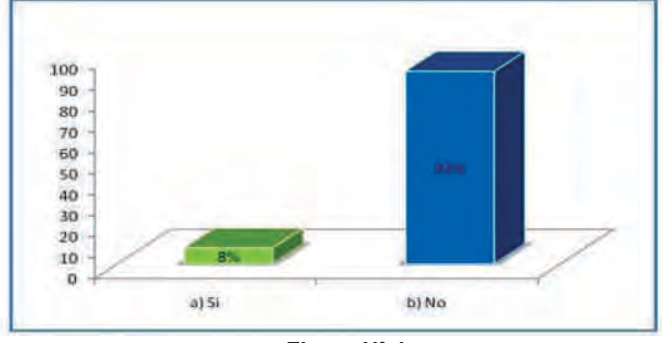

Figura $\mathrm{N}^{\circ} 4$

Son eficaces las sanciones penales impuestas en los delitos contra el honor prescritas en el Código Penal Peruano.

En la Figura $\mathrm{N}^{0} 3$ se observa que el $92 \%$ de los encuestados señala que las sanciones penales impuestas en los delitos contra el honor prescritas en el Código Penal Peruano "no" son eficaces; y sólo el 8\% señala lo contrario.

Tabla No1

Los resultados de los expedientes judiciales/ 2009 - 2010

Delitos contra el honor.

\begin{tabular}{|c|c|c|c|c|c|c|c|}
\hline No. & $N^{\circ}$ EXPEDIENTE & JUZGADO & QUERELLANTE & QUERELLADO & DELITO & RESULTADO & OBSERVACIOON \\
\hline 01 & $114-2009$ & $\begin{array}{l}\text { 1er Juzgada } \\
\text { Penal } \\
\text { Unipersonal }\end{array}$ & $\begin{array}{l}\text { Cadena Radial Sur } \\
\text { Peruana SA }\end{array}$ & $\begin{array}{l}\text { Julio Cèsar } \\
\text { Uchasara Coanta }\end{array}$ & $\begin{array}{l}\text { Difamación } \\
\text { Agravada }\end{array}$ & $\begin{array}{c}\text { Sentencia } \\
\text { Condenatoria }\end{array}$ & $\begin{array}{l}\text { Reservando el fallo condenatorio } \\
\text { con reglas de conducta Se fija } \\
\text { como reparación civil la cantidad } \\
\text { de cinco mil nuevos soles, con } \\
\text { costas del proceso en } \% \text { del } 50 \%\end{array}$ \\
\hline 02 & $222-2009$ & $\begin{array}{l}\text { 3er Juzgado } \\
\text { Penal } \\
\text { Unipersonal }\end{array}$ & $\begin{array}{l}\text { Jorge } \\
\text { Calderón }\end{array}$ & \begin{tabular}{|lr} 
Luis & Enrique \\
Antonio & Alfaro \\
Carcamo & \\
\end{tabular} & $\begin{array}{l}\text { Injuria } \\
\text { difamación }\end{array}$ & $\begin{array}{l}\text { Sentencia } \\
\text { Absolutoria }\end{array}$ & $\begin{array}{l}\text { Absuelve al querellado contra } \\
\text { delito de Calumnia y difamación } \\
\text { (por error se consigno injuria). y } \\
\text { como consecuencia el archivo } \\
\text { definitivo y anulación de } \\
\text { antecedentes. }\end{array}$ \\
\hline 03 & $466-2009$ & $\begin{array}{l}\text { 2do Juzgado } \\
\text { Penal } \\
\text { Unipersonal }\end{array}$ & $\begin{array}{l}\text { Oswaldo Anatolio } \\
\text { Olivos Bojorges }\end{array}$ & $\begin{array}{ll}\text { Nery } & \text { Doris } \\
\text { Obando Sagredo }\end{array}$ & $\begin{array}{l}\text { Difamación y } \\
\text { Calumnia }\end{array}$ & $\begin{array}{l}\text { Sentencia } \\
\text { Absolutona }\end{array}$ & $\begin{array}{l}\text { Absuelve a querellado del cargo } \\
\text { por los delitos de calumnia y } \\
\text { Difamación. en consecuencia se } \\
\text { dispone archivo definitivo de la } \\
\text { causa, asi como anulación de } \\
\text { antecedentes. Por falta de pruebas }\end{array}$ \\
\hline 04 & $591-2010$ & $\begin{array}{l}\text { 3er Juzgado } \\
\text { Penal } \\
\text { Unipersonal }\end{array}$ & $\begin{array}{l}\text { Antonia Maquera } \\
\text { Chura y otra }\end{array}$ & $\begin{array}{l}\text { Julian Marmani } \\
\text { Condori y otros }\end{array}$ & Difamación & $\begin{array}{l}\text { Sentencia } \\
\text { Absolutoria }\end{array}$ & $\begin{array}{l}\text { Absuelve a querellado y se se } \\
\text { dispone archivo definitivo de la } \\
\text { causa y la anulación de los } \\
\text { antecedentes. Por faita de } \\
\text { pruebas }\end{array}$ \\
\hline 05 & $821-2010$ & $\begin{array}{l}\text { 1er Juzgado } \\
\text { penal } \\
\text { Unipersonal }\end{array}$ & $\begin{array}{l}\text { Rodolfo } \\
\text { Chăvez }\end{array}$ & $\begin{array}{l}\text { Valentin Marcial } \\
\text { Galarza Humpire }\end{array}$ & $\begin{array}{l}\text { Calumnia y } \\
\text { Difamación }\end{array}$ & $\begin{array}{l}\text { Sentencia } \\
\text { Absolutoria }\end{array}$ & $\begin{array}{l}\text { Absuelve al querellado } \\
\text { consecuencia se dispone archivo } \\
\text { definitivo de causa y anulación de } \\
\text { antecedentes. Por falta de } \\
\text { pruebas. }\end{array}$ \\
\hline
\end{tabular}


De los expedientes analizados al menos el $27 \%$ de los expedientes ha sido declarado en abandono; el $20 \%$ han alcanzado sentencia absolutoria; otro $20 \%$ de los procesos ha sido archivados; el $11 \%$ ha sido declarados improcedente; el $10 \%$ han terminado en sobreseimiento; el $6 \%$ ha sido declarada inadmisible; el $5 \%$ de los expedientes han alcanzado sentencia condenatoria; $y$, el $1 \%$ ha sido declarado nulo. Concluyéndose que en su mayoría se ha dejado sin efecto todo lo actuado.

\section{Discusión}

El presente tema está referido a la despenalización de los Delitos contra el Honor del Código Penal, en donde se protegerá el derecho de Honor, a través de una Ley de Protección Civil, con la finalidad de que la persona afectada pueda ser indemnizada por el daño moral y perjuicios causados. Asimismo, dicho trámite debe ser efectuado a través del Proceso Civil - Vía Sumarísimo, llevándose a cabo en primer lugar en una Conciliación; en caso de no prosperar se realizará en audiencia única; y luego ser publicado en el diario de mayor circulación del País a costo del infractor, tal como señaló el Dr. Valle Riestra en su Proyecto de Ley presentado ante el Congreso de la República.

En este sentido, quienes se ven lesionados en cuanto a su honor o decoro, verían con mayor interés que el sujeto activo del delito les pague la reparación del daño pero desde el ámbito económico. Por tal motivo, considero que podría ser positivo despenalizar los Delitos contra el Honor y derivarlo a la jurisdicción civil siempre y cuando se incrementen los montos de las reparaciones; y por otro lado, se respeten los derechos fundamentales y principios que tienen la sociedad actual.

Asimismo, debo señalar que la despenalización de los Delitos contra el Honor es la propuesta más importante para plantear soluciones para la actuación tanto para el sujeto pasivo como activo; mediante la generación de la legislación civil para su cumplimiento; siempre y cuando, se actúe de acuerdo realidad social actual y así determinar adecuadamente la Tutela Procesal efectiva a la víctima.

\section{Conclusiones}

- El $88 \%$ de los profesionales del derecho de la especialidad en materia penal manifiestan que las penas tipificadas en los Delitos contra el Honor son ineficaces y por ello es necesaria la despenalización de este tipo de delitos del Código Penal Peruano.

- Las sanciones penales en los Delitos contra el Honor tipificadas en los artículos $130^{\circ}$ al $132^{\circ}$ del Código Penal; son muy bajas lo que no permite la protección jurídica del derecho al honor de las personas

- El $85 \%$ de los abogados litigantes en materia penal afirman que la reparación civil en los Delitos contra el Honor es ineficaz; por cuanto los mínimos montos establecidos en las multas previstas no permiten una eficaz protección al derecho al honor de las personas.

- En la vía extrapenal sería más viable el Principio de Tutela Procesal Efectiva, en los casos de vulneración del honor de las personas; puesto que permitiría el resarcimiento; así como de la indemnización de daños y perjuicios.

\section{Referencias bibliográficas}

1. ARIAS TORRES, LUIS A. Y MARÍA DEL CARMEN GARCÍA C (2006). MANUAL DE DERECHO PENAL, parte especial 4ta. Edición, Editorial San Marcos 2006 Lima - Perú.

2. BACIGALUPO, Enrique (1989). Manual de Derecho Penal. Editorial Temis S.A. Bogotá.

\section{Recibido: 15/09/13}

Aceptado para publicación: $04 / 11 / 2013$ 